\title{
Considerations about wastewater reuse in areas subjected to strong pressures in the South of Spain
}

\author{
José Manuel Nieto López ${ }^{1 *}$, Matías Mudarra Martínez ${ }^{1}$ and Bartolomé Andreo ${ }^{1}$ \\ ${ }^{1}$ Department of Geology and Centre of Hydrogeology of the University of Málaga \\ (CEHIUMA) \\ *corresponding author: nietolopezjm@uma.es
}

\begin{abstract}
Treated wastewater reuse is essential for water supply in areas where the pressure over water resources is high. This is the case of Costa del Sol and the Guadalhorce Valley, where a lot of water is required for urban, agricultural and recreational uses. Most of this water is coming from natural sources instead of being reused, which percentage varies over Spain. In these areas, located in the Málaga province (Andalucía region), less than $6 \%$ of treated wastewater is assigned for any kind of use (garden irrigation and golf courses is the major one). Trying to solve this lack of reclaimed water, a wetlands restoration project was carried out in the Guadalhorce River Mouth, near the city of Málaga. Several lagoons were created using treated wastewater. Results were satisfactory with a clear increase in biodiversity, but employing a reduced amount of replenished water, due to the very strict requirements of the regional government. So, a great effort must be done to improve water reusing, especially in parts were freshwater is scarce (like S Spain and Mediterranean area), but also to hire well trained technicians.
\end{abstract}

Keywords: Reuse, Spain, Restoration, Wastewater, Wetland.

\section{Introduction}

The Costa del Sol (Málaga, S Spain) is one of the main Spanish and European tourist destinations, which concentrates most of its visitors in summer. Besides, there are agricultural areas with high water needs, as the Guadalhorce Valley. Consequently, water demand is higher in this period and presents strong seasonal fluctuations over the year (Armagasilla, 2017).

In this region, water demand can be divided mainly in urban supply, garden/golf courses irrigation and agriculture, which is usually pumped from aquifers, although there exist a lot of surface water sources like reservoirs and water diversion from rivers. However, these water requirements can also generate a negative impact on groundwater dependent ecosystems, so it is necessary to look for different ways to satisfy the water needs of population for different uses. Thus, the objective of this work is to make a short review about water reuse in Spain and the performance of a study case where a wetland was created using treated wastewater. 


\section{Reclaimed water in Spain}

Alternatives for satisfying a higher water consumption are necessary due to population and tourism increasing, as well as the impact of Climate Change in this area (Gutiérrez et al., 2006; Ruiz Sinoga et al., 2010; among others). These studies predict that rainfall will suffer a reduction of 10-40 mm each season, but also an increment of $6{ }^{\circ} \mathrm{C}$ in the average temperature to the end of the 21 st Century. Moreover, in Spain only a $10.4 \%$ of treated water is reused (INE, 2016a), decreasing this percentage to $5.9 \%$ in the region of Andalucía and even $0 \%$ in Extremadura, Navarra, La Rioja, Ceuta and Melilla (Fig. 1). In the opposite, more than $45 \%$ of treated wastewater are reused in the Murcia and the Comunidad Valenciana regions. These values are possible because of the investment and the involvement of the regional Governments, although they are not the same everywhere in Spain.

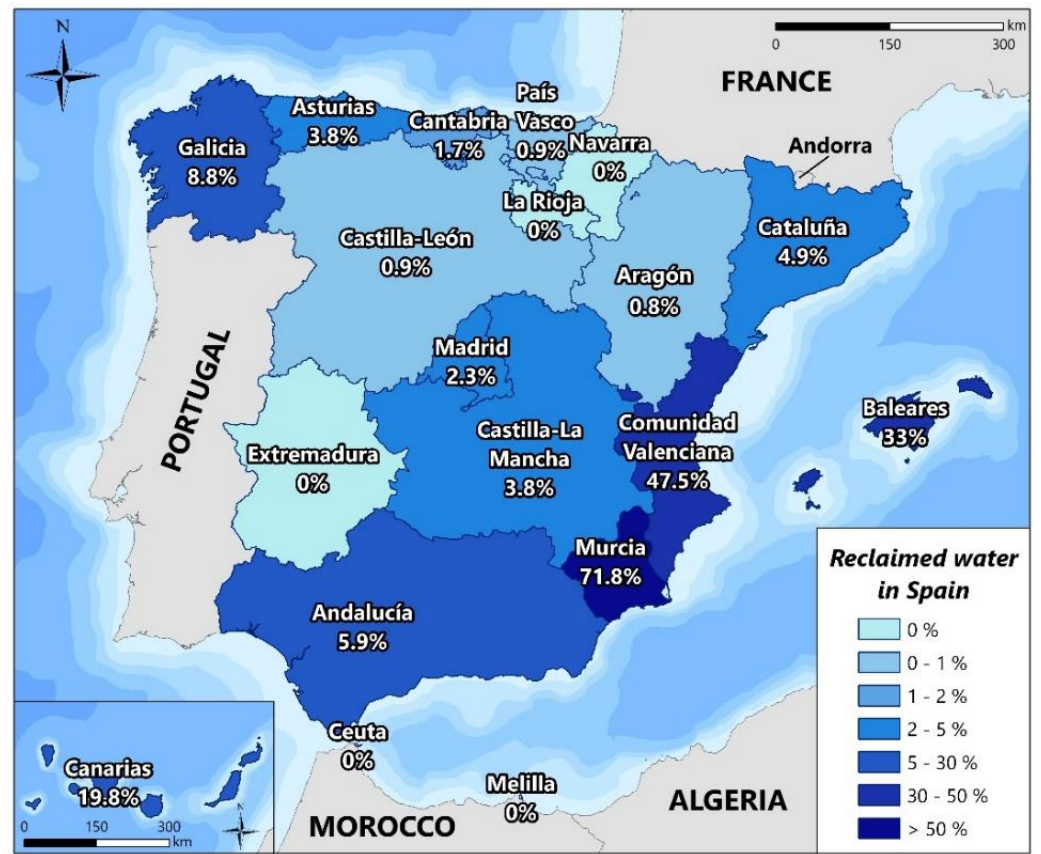

Fig. 1. Percentage of reused treated wastewater in Spain (INE, 2016a)

Reclaiming of treated wastewater is regulated by the law Real Decreto 1620/2007, por el que se establece el Régimen Jurídico de la Reutilización de las Aguas Depuradas (Order 1620/2007), which stablish the legal rules for treated wastewater reusing. This law sets the quality status that a treated wastewater has to have for its use, as well as the allowed and forbidden uses. It also develops some rules for determining responsi- 
bilities related with the maintenance of this quality (MMAMRM, 2010). The considered uses by the legislation are urban, agricultural, industrial, recreational and environmental, and their distribution varies significantly between regions (Fig. 2) (INE, 2016b). In Spain, reclaimed water is employed for gardening and recreational particularly in Andalucía, Galicia and Madrid, whereas in regions as Murcia, Comunidad Valenciana or Canarias, major treated wastewater reusing is for agriculture.

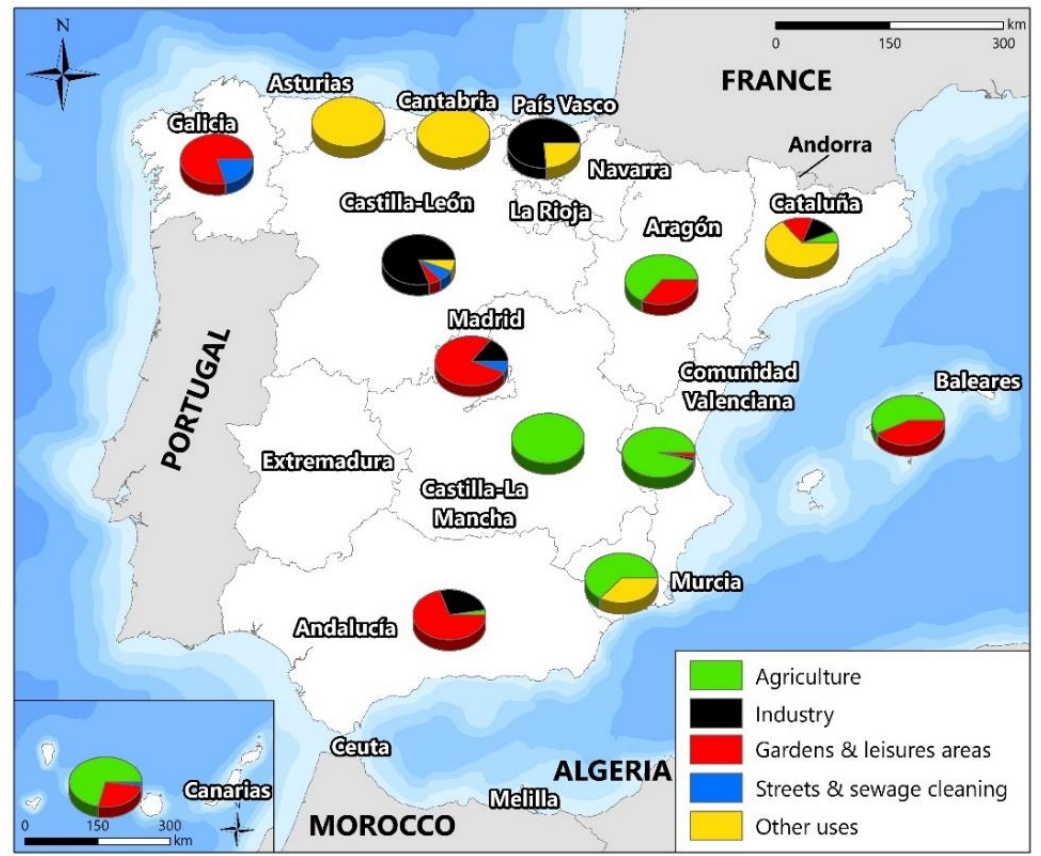

Fig. 2. Uses distribution of reclaimed water in Spain (INE, 2016b)

\section{A pilot project to reuse water in the South of Spain}

The Guadalhorce River Mouth is located in the vicinity of the city of Málaga, where a wetland restoration project was carried out for 3 years by reusing treated wastewater coming from a near wastewater treatment plant (WWTP). Restoration works were supported by the Coca-Cola Foundation (Atlanta, USA). The aims of the project were to create wetlands over some existing depressions, flooding them with treated wastewater, which would have facilitated the settlement of new animal and vegetal species, as well as serving as a hydraulic barrier against marine intrusion due to the dome of recharge created through the subjacent alluvial aquifer. 
However, very strict water quality requirements, imposed by the Regional Government, made very difficult to achieve a nice performance of the project. So, Total Phosphorus and Escherichia coli were the selected parameters to regulate the replenish, with maximum allowed values of $2 \mathrm{mg} / 1$ and $10^{4} \mathrm{CFU} / 100 \mathrm{ml}$, respectively. Treated wastewater had a mean concentration of $3.2 \mathrm{mg} / 1$ of Total Phosphorus and $10^{6} \mathrm{CFU} / 100$ $\mathrm{ml}$ of $E$. coli. These values were set by the Administration after considering the project as "Environmental use 5.4" into the current treated wastewater legislation, which includes wetlands maintenance, minimum outflows and similar ones. Here, the law establish that the minimum quality required will be studied case by case, so it will be in charge of the public technicians' criteria.

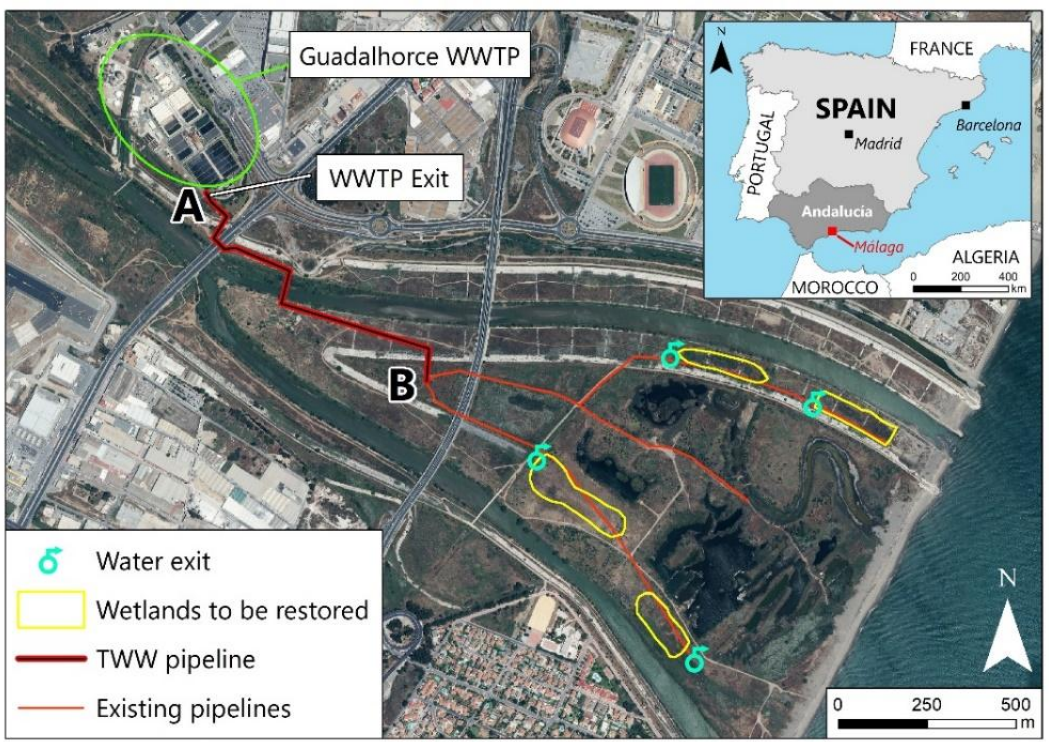

Fig. 3. Location and schematic explanation of the wetland's restoration project in Málaga, reusing treated wastewater. TWW: Treated wastewater; A: WWTP exit; B: connection point with existing pipelines.

It was very complicated to accomplish the Regional Government's requirements due to the low required values and to the budget limitations. The solution was the installation of a UV disinfection system in the WWTP to reduce the amount of E. coli. In addition, the limitation for Total Phosphorus was removed under a strict monitoring protocol for this parameter. These difficulties were responsible to not reaching the initial estimates of $650000 \mathrm{~m}^{3}$ of replenished water to the wetlands; only $73775 \mathrm{~m}^{3}$ were spilt $(\sim 10 \%)$. Despite of these issues, a two-pools wetland was created (Fig. 4) and new animal and vegetal species started to use it as refuge and feeding spot. In general, an improvement in the water quality of the wetland was also detected. Total Nitrogen and Phosphorus values were below the WWTP concentration in a lot of samples (Fig. 5), while E. coli 
concentration was always below $1000000 \mathrm{CFU} / 100 \mathrm{ml}$, showing a combined cleaning effect of vegetation, infiltration and sun radiation over the bacteria amount.

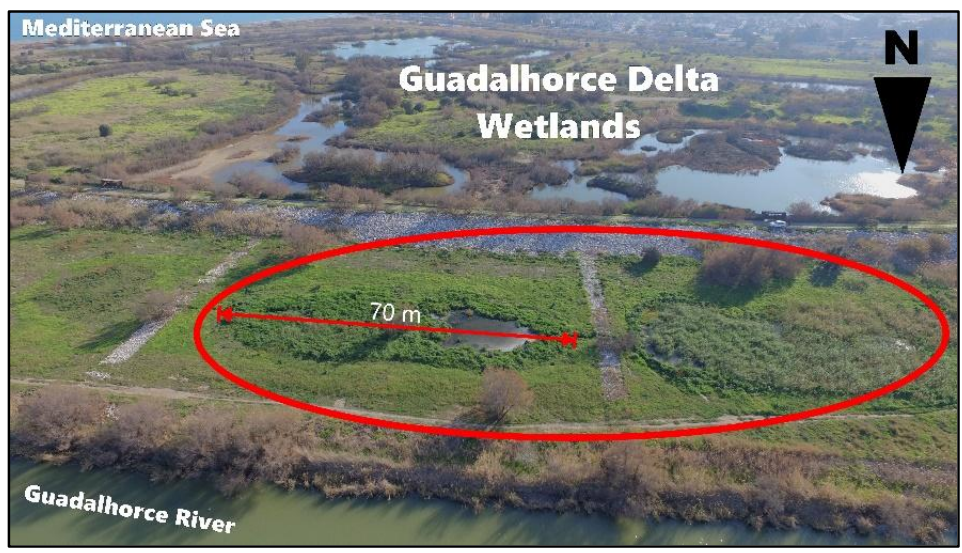

Fig. 4. Wetland created using treated wastewater (red circle) and Guadalhorce Delta Wetlands (up)

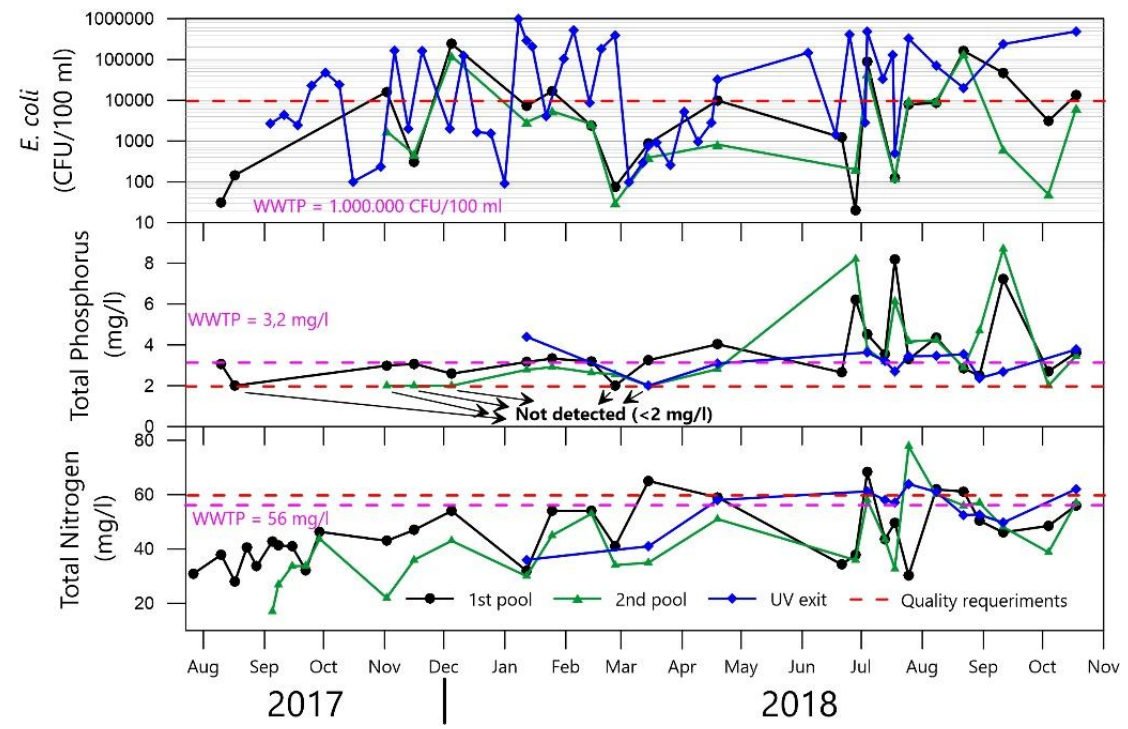

Fig. 5. Temporal variation of Total Nitrogen, Total Phosphorus and Escherichia coli concentration in the restored wetland during 15 months. 


\section{Concluding Remarks}

This work puts the focus on the Public Administration, that must adapt to the new water culture and to make a big effort in promoting the reuse of treated wastewater, but also political issues will is needed. These efforts must be even bigger in the Andalucía region, where the reclaiming percentages are very low and, furthermore, the environmental uses do not exist, practically. This is a result of the ambiguity and the relativity of the maximum allowed values criteria assignment for the considered parameters. In turn, this is in consonance with the lack of well-trained technical supervisors in the Government, who should have an interdisciplinary point of view for assessing the required parameters in the water destined for a specific environmental use.

\section{Acknowledgements}

This work is a contribution of the Research Group RNM-308 of the Andalusian Government to the project "Hydrological and environmental restoration of wetlands in the delta of Guadalhorce River (Málaga, Spain) reusing treated wastewater", funded by the Coca-Cola Foundation (Atlanta, US).

\section{References}

1. INE (2016a). Destino de las aguas residuales tratadas por comunidades y ciudades autónomas, lugar de destino y periodo. Instituto Nacional de Estadística. Madrid.

2. INE (2016b). Usos del agua reutilizada por comunidades y ciudades autónomas, tipo de uso y periodo. Instituto Nacional de Estadística. Madrid.

3. POCA BIBLIOGRAFÍ $\mathrm{A}_{i i}$ 